\title{
Efficient method of micropropagation and in vitro rooting of teak (Tectona grandis L.) focusing on large-scale industrial plantations
}

\author{
Emilio MENDOZA DE GYVES ${ }^{\mathrm{a} *}$, Juwartina Ida RoYANI ${ }^{\mathrm{a}, \mathrm{b}}$, Eddo RUGINI ${ }^{\mathrm{a}}$ \\ a Dipartimento Produzione Vegetale, Università degli Studi della Tuscia, Via S. C. de Lellis, 1, Viterbo, 01100, Italy \\ ${ }^{\mathrm{b}}$ Present address: Biotech Center, Agency for The Assessment and Application of Technology, Kawasan Puspiptek 630 Bld, Serpong, Indonesia
}

(Received 12 December 2005; accepted 2 March 2006)

\begin{abstract}
Multiple shoots of high quality were produced in vitro from nodal explants of Tectona grandis. An average of about 4 shoots/uninodal explant was obtained within 4 weeks of culture on Murashige and Skoog's (mMS) medium modified by $50 \%$ reduction in $\mathrm{NH}_{4} \mathrm{NO}_{3}$ concentration, supplemented with benzylaminopurine $\left(1.5 \mathrm{mg} \mathrm{L}^{-1}\right)$; indole-3-butyric acid $\left(0.01 \mathrm{mg} \mathrm{L}^{-1}\right)$ and gibberellic acid $\left(0.1 \mathrm{mg} \mathrm{L}^{-1}\right)$. The latter was applied both in the medium and by soaking the nodal segments for $10 \mathrm{~s}$. in a gibberellic acid solution of $100 \mathrm{mg} \mathrm{L}^{-1}$. Hundred percent of shoots rooted cultured on modified MS medium containing IBA $\left(0.5 \mathrm{mg} \mathrm{L}^{-1}\right)$ and putrescine $\left(160 \mathrm{mg} \mathrm{L}^{-1}\right)$. Putrescine promoted both strong and highly ramified roots and fast growing shoots during the rooting phase, conditioning the plantlets for a good survival and quality. Plantlets were transferred to jiffy pots for a short acclimatization stage in greenhouse where they survived at $100 \%$. This highly reproducible procedure can be adopted for large scale teak propagation.
\end{abstract}

plant growth regulator / putrescine / rooting / nodal explant / gibberellic acid

Résumé - Développement d'une méthode efficace de micropropagation et d'enracinement in vitro du teak (Tectona grandis L.) pour une production industrielle de plants. Des pousses multiples de haute qualité ont été produites in vitro à partir d'explants nodaux de Tectona grandis. Une moyenne d'environ 4 pousses par explant uninodal a été obtenue dans un délai de 4 semaines de culture sur un milieu de Murashige et Skoog modifié (mMS, $\mathrm{NH}_{4} \mathrm{NO}_{3}$ réduit de moitié), complété avec la benzylaminopurine (BA, $1.5 \mathrm{mg} \mathrm{L}^{-1}$ ), l'acide indole-3-butyric (IBA, $0.01 \mathrm{mg} \mathrm{L}^{-1}$ ) et l'acide gibbérélique $\left(\mathrm{GA}_{3}, 0.1 \mathrm{mg} \mathrm{L} \mathrm{m}^{-1}\right)$ dans le milieu et en imbibant les segments nodaux pendant $10 \mathrm{~s}$ dans la solution $100 \mathrm{mg} \mathrm{\textrm {L } ^ { - 1 }}$ de $\mathrm{GA}_{3}$. Cent pour cent d'enracinement in vitro des explants a été obtenu par la culture sur le même milieu de base mMS contenant IBA $\left(0.5 \mathrm{mg} \mathrm{L}^{-1}\right)$ et putrescine $\left(160 \mathrm{mg} \mathrm{L}^{-1}\right)$. La présence de la putrescine a permis d'obtenir des racines fortes et ramifiées, des pousses à croissance rapide pendant l'enracinement, donnant des plantes de qualité aptes à une bonne survie. Les plantes ont été endurcies et transférées dans des Jiffy pots pour une acclimatation brève en conditions de serre ayant pour résultat $100 \%$ de survie. Ce procédé hautement reproductible peut être adapté à grande échelle dans la propagation de teak du fait de l'efficacité du nombre de pousses obtenues (prolifération), de l'enracinement, de l'acclimatation et du bon développement des plantes.

régulateurs de croissance / putrescine / enracinement / explants nodaux / acide gibbérélique

\section{INTRODUCTION}

Teak (Tectona grandis L.), a leafy tree species, native to India, Myanmar, Laos and Thailand, is one of the world's premier hardwood timbers, attractive for its mellow colour, fine grain and durability. It is highly sought after for shipbuilding as well as interior and exterior luxury furnishings. The species is reported to cover 27.5 millions ha as natural forests and more than 3.3 millions ha as plantations in Asia. At present, teak ranks among the top five tropical hardwood species in terms of plantation area established worldwide [2, 15].

Establishment of new industrial forest plantations requires a lot of time before meeting the high demand for this precious timber. To enhance teak plantation development, the Indonesian government is making efforts to focus the research on improvement of the establishment of seed and clonal orchards to make the elite planting materials available for mass multiplication. In vitro propagation technique has become an efficient

* Corresponding author: emimendozagyv@yahoo.com.mx way for producing plants as uniform as possible on a large scale and in a short time for the plantation industry $[14,19]$. Teak is traditionally reproduced through seeds, but in most cases, germination is difficult due to the hard seed coat, low seed quality and late seed production. Poor germination rate leading to a low production of seedlings further contributes to the paucity of planting material $[1,25]$.

At present, even considering the very slow initial phase, in vitro micropropagation should be considered as a commercially feasible method for teak [10]. However, although numerous authors have been experimenting to establish an efficient, reproducible and simple system for micropropagating teak $[11,16,25,27]$, it still remains problematic due to the poor capacity of shoot proliferation, high susceptibility of shoots to vitrification and browning and the low frequency of in vitro rooting. None of the published protocols fully satisfies the requirements for commercial application in spite of the progress made on tissue culture of teak since the 1970s [8, 13, 18].

In tissue culture, the propagated shoots of teak may be rooted ex vitrum like conventional cuttings or in vitro. 
However, in vitro rooting is often preferred because the plants perform much better in terms of plant quality due to the advantage of possessing already roots during the acclimatization phase [6]. In most of the tissue culture laboratories that produce teak plants in Indonesia and in the world, rooting is done ex vitrum due to the low frequency of in vitro rooting, resulting in a too long procedure [3,25,27].

In this work we aimed to improve both the efficiency of shoot proliferation and in vitro rooting and also to accelerate the plant growth.

\section{MATERIALS AND METHODS}

\subsection{Explant source and sterilization}

Sixty shoot tips and single nodes of young twigs from a single sexually mature teak plus plant from Central Java Indonesia were cut off (at the end of may) from the explant source and were surface sterilized with ethanol $(70 \% \mathrm{v} / \mathrm{v})$ for $60 \mathrm{~s}$ and then dipped in a $0.05 \%$ mercuric chloride solution for 5-10 min. After rinsing three times with sterile distilled water, explants were dipped in 5-10\% commercial bleaching solution containing $5 \%$ sodium hypochloride and a few drops of Tween- 80 for 5-10 min, followed by three rinses in sterile distilled water.

\subsection{Culture establishment}

The nodal explants were then singly placed in test tubes $(25 \mathrm{~mm} \times$ $150 \mathrm{~mm}$ ) with basal MS [17] medium supplemented with 6-benzyl amino purine $\left(1.0 \mathrm{mg} \mathrm{L}^{-1}\right)$ and adenine sulphate $\left(20 \mathrm{mg} \mathrm{L}^{-1}\right)$, sucrose $(3 \%)$ and solidified with $0.6 \%$ agar supplied by Duchefa Biochemie (NL) to induce bud sprout and to select sterile shoots. Activated charcoal (Sigma, USA), $3 \mathrm{~g} \mathrm{~L}^{-1}$, was added to the medium to reduce browning. Medium $\mathrm{pH}$ was adjusted to 5.8 before autoclaving. After 30 days, the aseptic axillary shoots were transferred to a fresh medium of the same composition for 3 subcultures to produce a large number of shoots; then they were transferred to MS medium (free of PGR's) for 2 weeks in an attempt to eliminate any residual prior to placing the explants on several proliferation media. The aseptic shoots were cut into single nodes with their respective 2 leaves and placed, randomly distributed, into the different proliferation media. In general, from each shoot $4-5$ nodes were obtained.

\subsection{Shoot multiplication}

The culture media were: MS medium and modified MS (mMS) medium, the latter containing half the concentration of $\mathrm{NH}_{4} \mathrm{NO}_{3}$; both media contained 3\% sucrose, $0.6 \%$ (w/v) agar (Duchefa), $0.8 \%$ $(\mathrm{w} / \mathrm{v})$ pectin (from grape must) as anti-hyperhydricity agent, MS vitamins and PGR's as shown in Table I. The $\mathrm{pH}$ was adjusted to 5.8 before autoclaving. In some treatments, the explants (nodal segments) were dipped in pre-filtered aqueous solution of $\mathrm{GA}_{3}$, for $10 \mathrm{~s}$ at the concentration of $100 \mathrm{mg} \mathrm{L}^{-1}$, prior to being placed into the jars $\left(+\mathrm{GA}_{3}\right.$, Tab. I).

Four glass jars $(580 \mathrm{~mL})$ with glass cover were used per treatment. Each jar contained 10 uninodal explants in $100 \mathrm{~mL}$ of medium. The cultures were covered with a polyethylene film and incubated at
Table I. Combinations of plant growth regulators (PGRs) used for shoot proliferation of teak.

\begin{tabular}{|c|c|c|c|c|c|}
\hline \multirow[t]{2}{*}{ Media } & \multicolumn{4}{|c|}{ Plant growth regulator $\left(\mathrm{mg} \mathrm{L}^{-1}\right)$} & \multirow{2}{*}{$\frac{\text { Pulse treatment }}{\mathrm{GA}_{3}}$} \\
\hline & BAP & AdS & IBA & $\mathrm{GA}_{3}$ & \\
\hline mMS-A & 1.5 & - & 0.01 & 0.1 & \\
\hline $\mathrm{mMS}-\mathrm{A}+\mathrm{GA}_{3}$ & 1.5 & - & 0.01 & 0.1 & + \\
\hline mMS-B & 1.5 & - & 0.01 & 0.5 & \\
\hline $\mathrm{mMS}-\mathrm{B}+\mathrm{GA}_{3}$ & 1.5 & - & 0.01 & 0.5 & + \\
\hline MS-A & 0.5 & 20.0 & - & - & \\
\hline $\mathrm{MS}-\mathrm{A}+\mathrm{GA}_{3}$ & 0.5 & 20.0 & - & - & + \\
\hline MS-C & 0.5 & 20.0 & - & 2.0 & \\
\hline $\mathrm{MS}-\mathrm{C}+\mathrm{GA}_{3}$ & 0.5 & 20.0 & - & 2.0 & + \\
\hline
\end{tabular}

* Explants (nodal segments) were dipped in pre-filtered aqueous solution of $\mathrm{GA}_{3}$ at $100 \mathrm{mg} \mathrm{L}^{-1}$ for $10 \mathrm{~s}$.

approximately $24^{\circ} \mathrm{C}, 16$-h light (fluorescent lamps with photon lux light intensity of $40 \mu \mathrm{mol} \mathrm{m} \mathrm{m}^{-2} \mathrm{~s}^{-1}$ ). The percentage of explants initiating shoots, the number of shoots per explant, number of nodes per shoot, shoot length and basal callus fresh weight were recorded after 4 weeks of culture. Callus was removed from the shoots before weighing. The micropropagation cycle consisted of a monthly subculture of nodal segments after removal of the new shoots onto fresh medium. Data were collected three times at a two month interval and subjected to one way analysis of variance (ANOVA). The mean responses among the different treatments were compared applying the Student-Newman-Keuls (SNK) method using SigmaStat for Windows Version 2.0 (Jandel Corporation, Erhrath, Germany). A value of $p<0.05$ was considered significant.

\subsection{Rooting}

Elongated shoots derived from nodal explants (grown on mMS$A+G_{3}$ ), were excised and their response to a range of rooting treatments was determined. The rooting medium consisted of mMS plus MS vitamins and 3\% sucrose and solidified with $0.6 \%$ of agar. Indole3-butyric acid (IBA) was tested either alone (at 0, 0.5, 1, 1.5 $\mathrm{mg} \mathrm{L}^{-1}$ ) or in combination with putrescine $\left(160 \mathrm{mg} \mathrm{L}^{-1}\right)$. The cultures were initially maintained for 6 days under dark and then exposed to light and temperature as mentioned above. Eight shoots were inserted with their basal endes into $100 \mathrm{~mL}$ of medium in a $580 \mathrm{~mL}$ glass jar. Each treatment consisted of four jars, every one containing eight explants. All experiments were repeated two times. The percentage of rooted shoots, the total number of roots and root length for each rooted microcutting were evaluated after 4 weeks of culture on the rooting medium.

The plantlets were transplanted to jiffy pots (round $8 \times 8 \mathrm{~cm}$ ) containing a soil: vermiculite $(1: 1)$ mixture. Initially plantlets were covered with a polyethylene film, which was gradually eliminated in two weeks time. Plants were transferred to pots and placed in a greenhouse for completing their acclimatization $\left(28 \pm 2{ }^{\circ} \mathrm{C} \mathrm{RH} 90 \%\right)$.

The data were subjected to one way analysis of variance (ANOVA) and a pairwise multiple comparison procedure was applied using the Student-Newman-Keuls (SNK) method to compare the mean responses among the different treatments. The SigmaStat program for Windows, Version 2.0 (Jandel Corporation) was used. A value of 


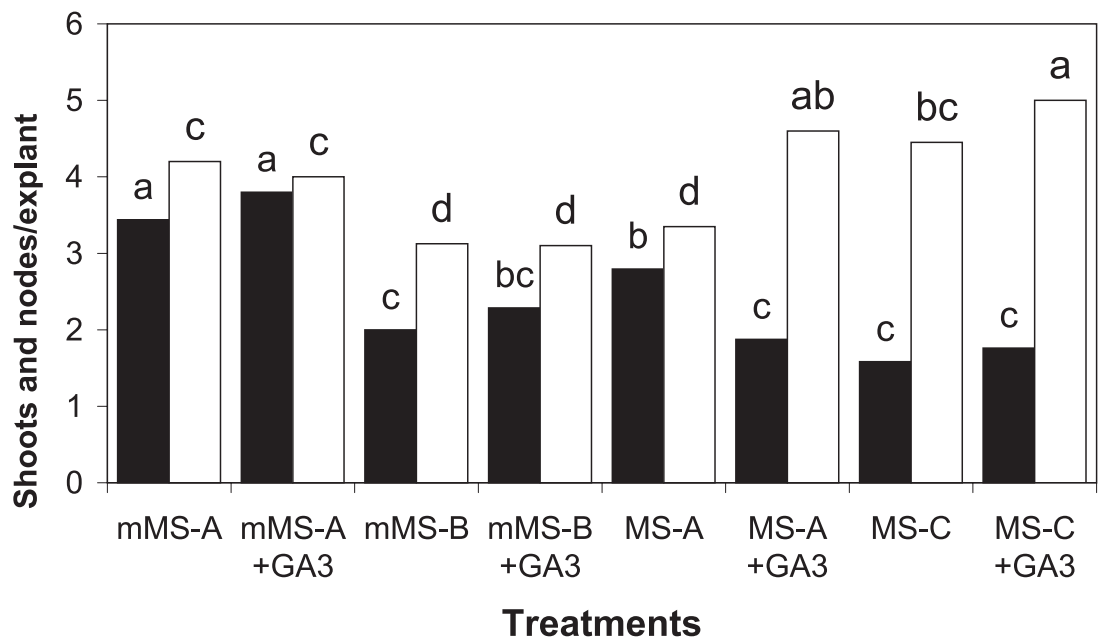

Figure 1. Effect of medium composition on average number of axillary shoots per node ( $\square$ ) and number of nodes ( $\square$ ) per shoot after one month of culture. Values represent the means (40 replicates per treatment; repeated twice) and the same letters (within the same bars) indicate non significant difference according to SNK test at $P<0.05$. MS: Murashige and Skoog medium; mMS: modified Murashige and Skoog medium.

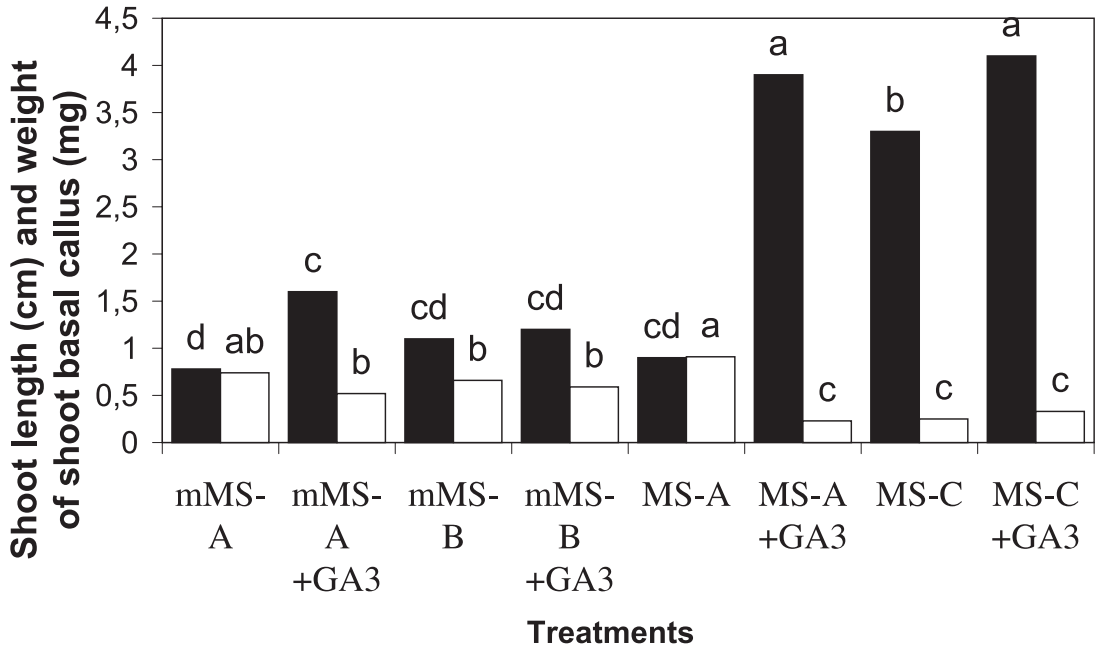

Figure 2. Effect of medium composition on average length of axillary shoots ( $\mathbf{\square})$ and callus production at the base of the explants ( $\square$ ) after one month of culture. Values represent the means (40 replicates per treatment; repeated twice) and the same letters (within the same bars) indicate non significant difference according to SNK test at $P<0.05$. MS: Murashige and Skoog medium; mMS: modified Murashige and Skoog medium.

$p<0.05$ was considered significant. To analyze the data on rooting percentages, arcsin square root transformation was used.

\section{RESULTS AND DISCUSSION}

\subsection{Explant responses}

Approximately $80 \%$ of the node explants remained aseptic. Three to four days after incubation on establishment medium, the axillary buds started to burst. At least, one axillary shoot developed per node, rarely two, however only one was able to elongate. The process of teak culture establishment in this experiment coincided with Devi et al. [7], who reported that axillary shoots developed after 7-10 days and with Tiwari et al. [25] who observed axillary shoots after 6 weeks on several nodes.

\subsection{Shoot proliferation}

According to SNK test, among the media tested, modified MS, without adenine sulphate, was superior to MS in terms of average number of shoots per explant resulting in a statistically significant difference with 3.8 axillary shoots per explant of MS-A+GA $\mathrm{G}_{3}$ medium versus 2.7 shoots in MS-A medium supplemented with adenine sulphate (Fig. 1). $\mathrm{GA}_{3}$, both in the medium or used by soaking the explants, was effective in full MS medium, where it slightly increased number of nodes and drastically increased shoot length (Figs. 1 and 2). Negative 


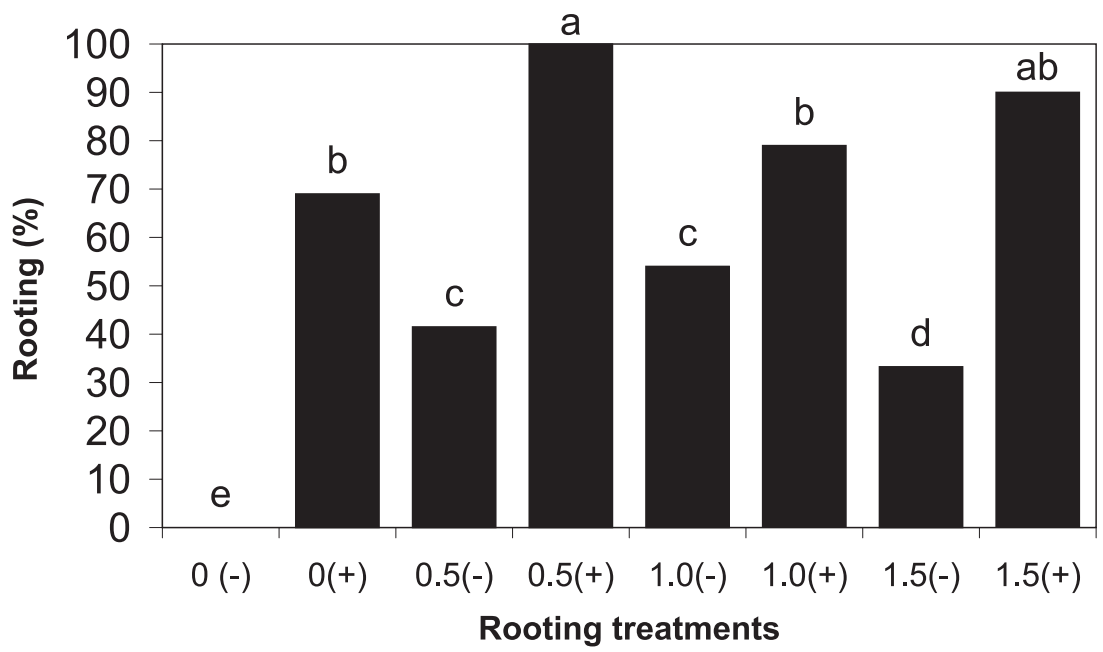

Figure 3. Effect of different IBA concentrations $\left(\mathrm{mg} \mathrm{L}^{-1}\right)$ and the presence $(+)$ or absence $(-)$ of putrescine $\left(160 \mathrm{mg} \mathrm{L}^{-1}\right)$ on rooting percentage of shoots obtained on mMS-A+GA . Values represent the means (32 replicates per treatment; repeated twice) and the same letters indicate non significant difference according to SNK test at $P<0.05$.

correlation between shoot length and basal callus formation was observed (Fig. 2). The callus production on the basal part of the shoots was very frequent in this species, even in absence of auxins [12, 20,25]. Explants immersed in $\mathrm{GA}_{3}$ showed reduced basal callus and longer shoots elongation on both media (Fig. 2). The media: mMS-A and $\mathrm{mMS}-\mathrm{A}+\mathrm{GA}_{3}$ presented the best response with respect to a number of axillary shoots, however the latter appeared more suitable for proliferation since it showed the highest number of shoots per nodal segment (3.8) and relatively high number of nodes per shoot (4), giving the highest multiplication factor reported for teak in the literature. In addition, the medium mMS-A+GA 3 showed a better length of shoots regarding the mMS-A and also with a lighter basal callus, avoiding a further step for elongation of shoots (Fig. 2). The shoots derived from this medium could be rooted or cut into single node segments to continue the multiplication cycle (Figs. 5a and 5b).

Devi et al. [7] proposed a two step protocol in which they obtained more than 200 shoots from a single explant in three months. Our results showed that more than 800 shoots can be obtained in a similar period of time, through the dissection of the shoots into nodal explants avoiding a further subculture onto shoot elongation medium to prepare shoots for rooting phase. A protocol for micropropagation of teak using MS basal medium supplemented with BAP and kinetin was suggested by Goswami et al. [12]. In this protocol, an average of 3.7 shoots per explant in 8 weeks was produced, but the shoots required further subculture onto elongation medium. In an attempt to save time by avoiding an additional subculture step, we used $\mathrm{GA}_{3}$ in the proliferation medium to produce shoots with longer internodes therefore, preparing the new shoots to be used for rooting, and at the same time, the basal callus size was reduced.

According to the literature, BAP has been the most commonly used in micropropagation of teak alone or with kinetin $[12,13]$. High concentration of BAP $\left(5 \mathrm{mg} \mathrm{L}^{-1}\right)$ was applied for a few hours [25]. However, high concentrations of BAP can be inhibitory to the growth of axillary bud sprouts and can present some risks of unexpected abnormalities of new shoots after this treatment such as vitrification [5]. On the other hand, decreasing the cytokinin concentration generally reduces the multiplication rate. Ammonium is another compound involved in vitrification [4]. We took steps to overcome vitrification problems by modifying the MS medium (reducing the ammonium quantity) and by adding pectin (from grape must) $[24,26]$ to reduce the water content in the medium and by adding $\mathrm{GA}_{3}$ since this was beneficial in olive [24]. According to general observations, these changes probably contributed in the improvement of the culture quality reducing visual vitrification symptoms.

\subsection{Rooting}

After 4 weeks of culture, on the rooting medium, rooting took place only in the presence of auxin or putrescine. IBA alone induced $30-50 \%$ rooting depending on its concentration, producing swollen and brittle roots. Putrescine alone $\left(160 \mathrm{mg} \mathrm{L}^{-1}\right)$ promoted about $70 \%$ of rooting. Rooting reached $100 \%$ when putrescine was combined with $0.5 \mathrm{mg} \mathrm{L}^{-1}$ IBA (Fig. 3). Callus formation at the base of shoots increased with increasing concentrations of IBA. The number of roots per explant was low with the lowest IBA concentration, but increased when IBA was combined with putrescine (Fig. 4). The use of a low concentration of IBA is advisable since it does not interfere with shoot growth, root elongation and keeps the basal callus small, however, it induces only a few thin roots without lateral ramifications. The combination of IBA with putrescine resulted in vigorous roots with multilateral ramifications. Roots emerged at the base of shoots after 2 weeks. An additional 2 weeks on this medium increased the number of roots and promoted shoot elongation (Figs. 5c and 5d). Plant 


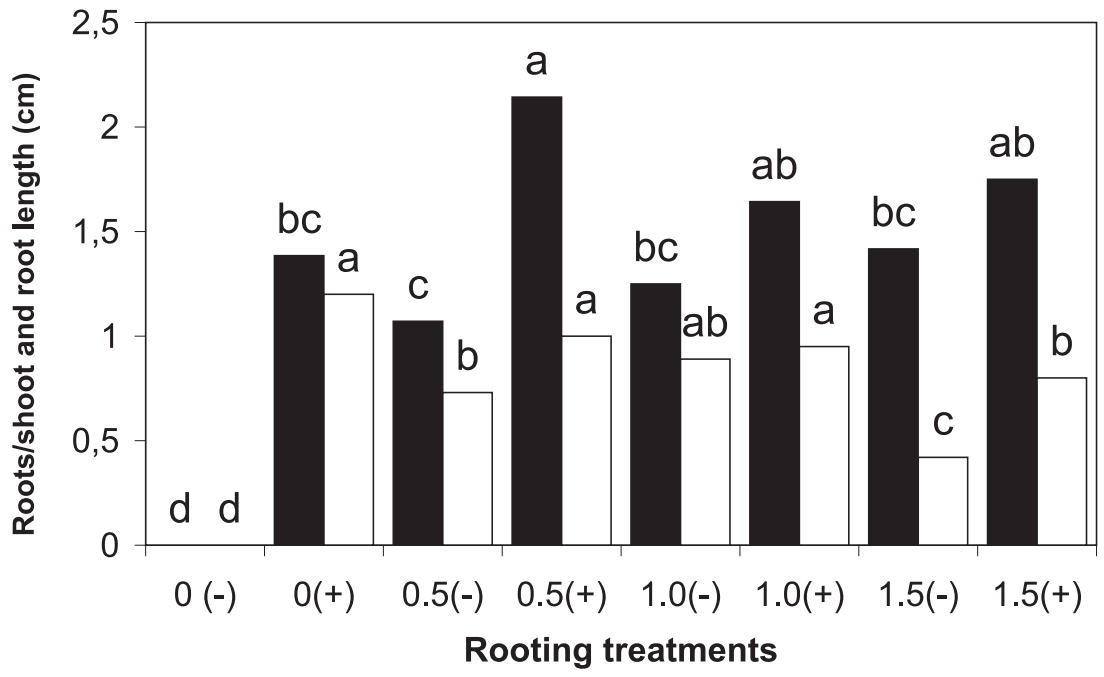

Figure 4. Effect of different IBA concentrations $\left(\mathrm{mg} \mathrm{L}^{-1}\right)$ and the presence $(+)$ or absence $(-)$ of putrescine $\left(160 \mathrm{mg} \mathrm{L}^{-1}\right)$ on number of roots per explant ( $\mathbf{\square})$ and root length $(\square)$ after one month of incubation of shoots obtained on $\mathrm{mMS}-\mathrm{A}+\mathrm{GA}_{3}$. Values represent the means (32 replicates per treatment; repeated twice) and same letters within the same colour of bars indicate non significant difference according to SNK test at $P<0.05$.
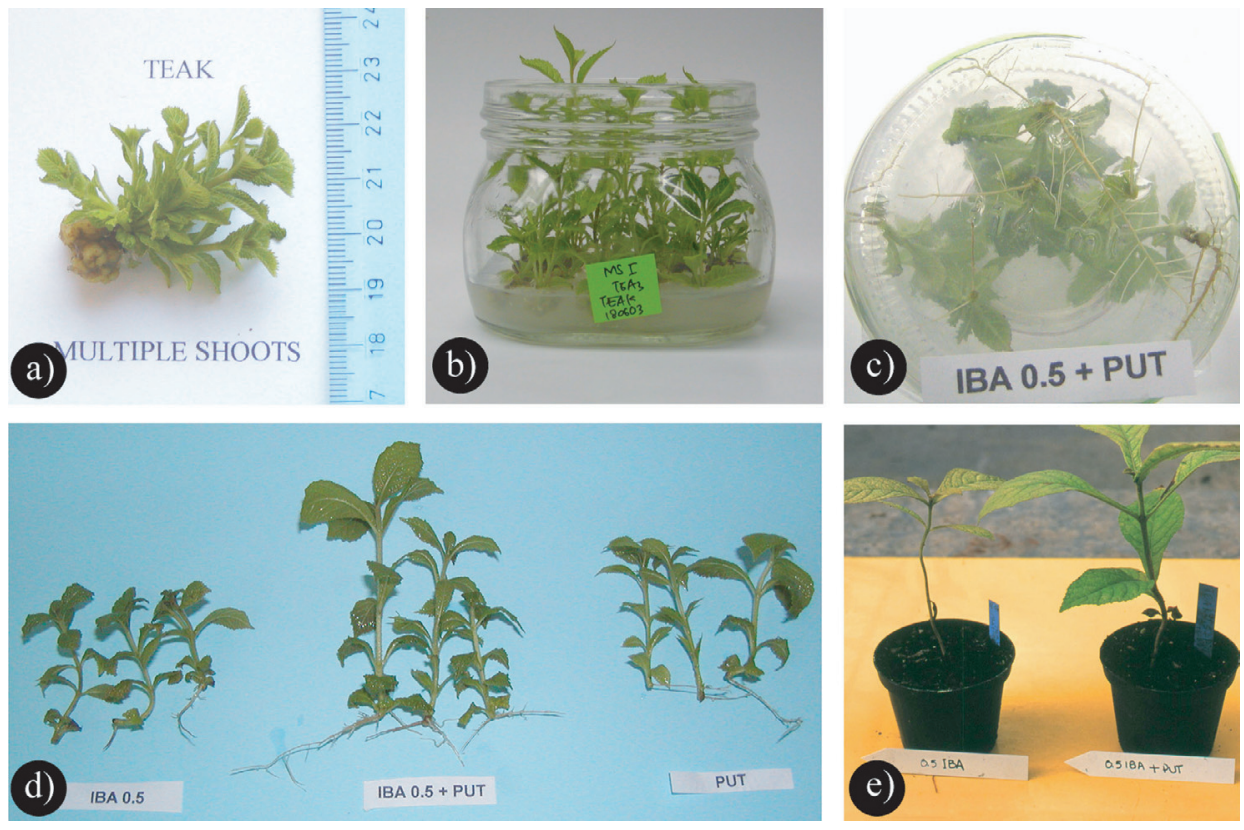

Figure 5. Micropropagation, in vitro rooting and acclimatization of teak: (a) multiple shoots in proliferation developed on modified MS medium; (b) shoot proliferation from explants dipped for $10 \mathrm{~s}$ in $\mathrm{GA}_{3}$ solution before culturing on medium; (c) effect of putrescine on root ramification; (d) effect of different treatments on rooting after four weeks; (e) comparison between shoots rooted in vitro with IBA alone or with putrescine (+ Put). Note a better growth of the plantlet rooted in presence of putrescine.

acclimatization after rooting on IBA + putrescine was $100 \%$ successful, the plants had a good root system and no morphological abnormalities. The growth was higher in plants when rooted with IBA combined with putrescine (Fig. 5e).

The application of exogenous polyamines to increase rooting and to improve root quality, was first demonstrated in olive. When the polyamines were combined with auxins, it promoted early rooting and increased the final rooting percent- age and the number of roots per explant [21,22]. Putrescine is involved in root induction by increasing the activity of total peroxidases at the base of explants and promotes rapid root growth and increases rooting frequency [23]. The positive effect of polyamines has been correlated to the low endogenous level of polyamines found in olive shoots. In species with high endogenous polyamine levels they had no beneficial effect [22]. Perhaps teak contains low concentration of 
polyamines, as does olive, and requires a reduction of endogenous auxins during the root induction phase. This may occur by $\mathrm{H}_{2} \mathrm{O}_{2}$ freeing from polyamine catabolism, which is well known to increase peroxidase activity reducing IAA in the induction phase [23]. Putrescine not only induces an increase in rooting percentage itself, but it requires a low concentration of auxin for improving root quality, avoiding bud dormancy caused normally by high concentration of auxins used during the rooting phase. The absence of bud dormancy is essential for acclimatization and subsequent shoot development.

Gangopadhyay et al. [9] carried out rooting in a liquid medium supplemented with IBA and IAA, but the percentage of the survival of plants after transplantation was relatively low $(77 \%)$, and the number of roots per plant has only $1.2 \pm 0.2$. In alternative to in vitro rooting, ex vitrum rooting of teak has been also proposed but survival of plantlets did not exceed $77 \%$ [25]. Our results offer better performance in terms of rooting percentage (100\%), plant survival (100\%) and rapid growth.

\section{CONCLUSIONS}

This study provides an efficient in vitro propagation method which could be commercially feasible for teak, by providing a protocol for producing genetically uniform plants from selected genotypes. This work showed the highest number of micropropagated shoots reported for teak, up to now, in the literature and in a relative short period of time, producing about 4 shoots with 4 nodes within 4 weeks. Particular emphasis should be done to the use of putrescine, which in combination with low concentration of auxin, in rooting medium, was essential in stimulating high rooting percentage with high quality of roots, resulting in fast growing plantlets during acclimatization phase, reaching $100 \%$ of plant survival. Some steps were important for improving quality of shoots both during proliferation and rooting phases, aimed at reducing vitrification problems and aimed at improving shoot length and rooting percentage, by modifying the medium composition in terms of salt balance, type of gelling agent, by adding pectin of must wine, hormones and method of their administration, resulting in a reduction of the process time from the usual 4-5 months reported in the literature to less than 3 months including the greenhouse acclimatization period.

\section{REFERENCES}

[1] Bonal D., Monteuuis O., Ex vitro survival, rooting and initial development of in vitro rooted vs. unrooted microshoots from juvenile and mature Tectona grandis genotypes, Silvae Genet. 46 (1997) 301-306.

[2] Dah U.S., Baw U.S., Regional teak marketing and trade, Proceedings of third regional seminar on teak, Indonesia, 2001, pp. 1-14.

[3] Castro R.D., Diaz G.J., Linero J.C., In vitro clonal propagation of elite trees of teak (Tectona grandis L.), Rev. Colombiana Biotec. 4 (2003) 49-53.

[4] Daguin F., Letouze R., Ammonium-induced vitrification in cultured tissues, Physiol. Plant. 66 (1986) 94-98.
[5] Debergh P.C., Effects of agar brand and concentration on the tissue culture medium, Physiol. Plant. 59 (1983) 270-276.

[6] De Klerk G.J., Rooting of microcuttings: Theory and practice, In Vitro Cell. Dev. Biol. 38 (2002) 415-422.

[7] Devi Y.S., Mukherjee B.B., Gupta S., Rapid cloning of elite teak (Tectona grandis L.) by in vitro multiple shoot production, Indian J. Exp. Biol. 32 (1994) 668-671.

[8] Dhruva B.R., Rao A.V.R., Srinivasan R., Venkataraman K., Structure of a quinone from teak tissue culture, Indian J. Chem. 10 (1972) 683-685.

[9] Gangopadhyay G., Das S., Mitra S.K., Poddar R., Modak B.K., Mukherjee K.K., Enhanced rate of multiplication and rooting through the use of coir in aseptic liquid culture media, Plant Cell Tiss. Org. Cult. 68 (2002) 301-310.

[10] Gangopadhyay G., Gangopadhyay S.B., Poddar R., Grupta S., Mukherjee K.K., Micropropagation of Tectona grandis: assessment of genetic fidelity, Biol. Plant. 46 (2003) 459-461.

[11] Gill S.S., Gupta R.P., Pandher M.S., In vitro propagation of teak, India. J. Res. 28 (1991) 507-510.

[12] Goswami H., Keng C.L., Teo C.K.H., In vitro shoot multiplication of Tectona grandis, J. Biosci. (Penang, Malaysia) 10 (1999) 47-54.

[13] Gupta P.K., Nadgir A.1., Mascarenhas A.F. Jaganathan V., Tissue culture of forest trees - Clonal multiplication of Tectona grandis (teak) by tissue culture, Plant Sci. Lett. 17 (1980) 259-268.

[14] Krishnapillay B., Silviculture and management of teak plantations, in: Unasylva, No. 201, Teak, Int. J. Forestry Forest Ind. (FAO) (2000) 51- 2000/2.

[15] Maldonado G., Louppe D., Challenges of teak in Côte d'Ivoire, in: Unasylva, No. 201, Teak, Int. J. Forestry Forest Ind. (FAO) (2000) 51- 2000/2.

[16] Monteuuis O., Bon M.C., Goh D.K.S., Teak propagation by in vitro culture, Bois For. Trop. 256 (1998) 1-11.

[17] Murashige T., Skoog F., A revised medium for rapid growth and bioassays with tobacco tissue cultures, Physiol. Plant. 15 (1962) 473-497.

[18] Narasimhan R., Dhruva B., Paranjpe S.V., Kulkarni D.D., Mascarenhas A.F., Davis S.B., Tissue culture of some woody species, Proc. Indian Acad. Sci. 71 (1970) 204-212.

[19] Pandey D., Brown C., Teak: a global overview, in: Unasylva, No. 201, Teak, Int. J. Forestry Forest Ind. (FAO) (2000) 51- 2000/2.

[20] Royani J.I., Riyadi A., Novita L., Plant micropropagation of teak (Tectona grandis. L. f) in vitro, Proceedings of National conference: Technology for country 2001, 2001, pp. 26-28.

[21] Rugini E., Jacoboni A., Luppino M., Role of basal shoot darkening and exogenous putrescine treatments on in vitro rooting and on endogenous polyamine changes in difficult-to-root woody species, Sci. Hortic. 53 (1993) 63-72.

[22] Rugini E., Involvement of polyamines in auxin and Agrobacterium rhizogenes-induced rooting of fruit trees in vitro, J. Am. Soc. Hortic. Sci. 117 (1992) 532-536.

[23] Rugini E., Di Francesco G., Muganu M., Astolfi S., Caricato G., The effects of polyamines and hydrogen peroxide on root formation in olive and the role of polyamines as an early marker for rooting ability, in: Altman and Waisel (Eds.), Biology of root formation and development, Plenum Publishing Co., New York, 1997, pp. 65-73.

[24] Rugini E., Tarini P., Rossodivita M.E., Control of shoot vitrification of almond and olive grown in vitro, Acta Hortic. 212 (1987) $177-183$.

[25] Tiwari S.K., Tiwari K.P., Siril E.A., An improved micropropagation protocol for teak, Plant Cell. Tiss. Org. Cult. 71 (2002) 1-6.

[26] Whitehouse A.B., Marks T.R., Edwards G.A., Control of hyperhydricity in Eucalyptus axillary shoot cultures grown in liquid medium, Plant Cell. Tiss. Org. Cult. 71 (2002) 245-252.

[27] Yasodha R., Sumathi R., Gurumurthi K., Improved micropropagation methods for teak, J. Trop. For. Sci. 17 (2005) 63-75. 